\begin{tabular}{ll|l} 
Case Reports in & \multicolumn{2}{c}{ Case Rep Gastroenterol 2013;7:281-286 } \\
\cline { 2 - 3 } Gastroenterology & $\begin{array}{l}\text { DOI: } 10.1159 / 000354145 \\
\text { Publisned onIIne: July 13, } 2013\end{array}$ & $\begin{array}{l}\text { ○ 2013 S. Karger AG, Basel } \\
1662-0631 / 13 / 0072-0281 \$ 38.00 / 0 \\
\text { www.karger.com/crg }\end{array}$ \\
\hline & $\begin{array}{l}\text { This is an Open Access article licensed under the terms of the Creative Commons Attribution- } \\
\text { NonCommercial-NoDerivs 3.0 License (www.karger.com/OA-license), applicable to the } \\
\text { online version of the article only. Distribution for non-commercial purposes only. }\end{array}$
\end{tabular}

\title{
Neuromyelitis Optica: An Often Forgotten Cause of Intractable Nausea and Vomiting
}

\author{
Chijioke Enweluzo Pradeep Yarra \\ Section on Hospital Medicine, Department of Internal Medicine, Wake Forest School of \\ Medicine, Winston Salem, N.C., USA
}

\section{Key Words}

Neuromyelitis optica $\cdot$ Intractable nausea and vomiting $\cdot \mathrm{NMO}-\mathrm{IgG}$

\begin{abstract}
Neuromyelitis optica, also known as Devic's disease, is a rare autoimmune disorder in which a patient's immune system affects the optic nerves and the spinal cord, leading to loss of vision and spinal cord dysfunction. We present our experience with a 38-year-old female who presented to our facility with complaints of intractable nausea and vomiting. After extensive evaluation, she was found to have neuromyelitis optica. Her symptoms completely resolved following institution of appropriate therapy. She made a significant recovery and has since been placed on chronic immunosuppressive therapy. Through this article we hope to bring attention to a significant cause of intractable nausea and vomiting that may often be forgotten in general medicine or gastroenterology services.

(c) 2013 S. Karger AG, Basel
\end{abstract}

\section{Introduction}

Intractable nausea and vomiting is a commonly encountered problem in any general medicine or gastroenterology service. Several causes from infection to chronic medical conditions, such as diabetic gastroparesis and gastroparesis due to multiple causes, can be listed. Neuromyelitis optica (NMO), also known as Devic's disease, is a rare autoimmune disorder in which a patient's immune system attacks their own nervous system, especially the optic nerves and the spinal cord, leading to loss of vision and spinal cord dysfunction [13]. The likely target of the autoimmune attack, at least in some patients with NMO, has been identified as a protein of the nervous system astrocytes called aquaporin 4 . 
Typically, NMO is diagnosed in patients presenting with a rapid onset of blindness in one or both eyes, followed within days or weeks by varying degrees of paralysis in the arms and legs. In most cases, however, the interval between optic neuritis and transverse myelitis is significantly longer, in many cases can occur after some years of quiescence. After the initial attack, NMO follows a largely unpredictable course. Besides muscle weakness and reduced sensation, bladder and bowel incontinence have also been reported. The disease can also occur as clusters of attacks months or years apart, followed by partial recovery during periods of remission. This is considered a relapsing form of the disease. This relapsing form of NMO mostly affects women. The female to male ratio is $>4: 1$. Another form of NMO, in which an individual only has a single, severe attack extending over a month or two, is most likely a distinct disease that affects men and women with equal frequency. The onset of NMO varies from childhood to adulthood, with two peaks, one in childhood and the other in adults (mostly in their 40s) [1-3]. For a while, NMO was considered to be a severe variant of multiple sclerosis (MS) because both can cause attacks of optic neuritis and myelitis. Recent discoveries, however, suggest it is a separate disease [2,3]. NMO is different from MS in the severity of its attacks and its tendency to solely strike the optic nerves and spinal cord at the beginning of the disease. Symptoms outside of the optic nerves and spinal cord are rare, although certain symptoms, including uncontrollable vomiting and hiccups, are now recognized as relatively specific symptoms of NMO that are due to brainstem involvement, specifically the area postrema [4].

\section{Clinical Course}

We present our encounter with a 38-year-old female with no past medical history who presented to the emergency department with complaints of intractable nausea, vomiting, hiccups and abdominal pain. Around thanksgiving 2012, she had had bronchitis and sinusitis. She had been treated with Tylenol Cold and Cough, a Z-PAK, inhalers and Tessalon Perles. This had progressively worsened into intractable nausea and vomiting about 4 days following thanksgiving and lasted till presentation, which was about 2 weeks after onset. She gave a history of vomiting about 18 times per day with preceding nausea. She had hiccups after every episode of vomiting.

On presentation, physical examination as well as laboratory and radiological data were unremarkable. Complete blood count revealed hemoglobin of $10.1 \mathrm{~g} / \mathrm{dl}$, a hematocrit of $31.2 \%$, a platelet count of $225 \times 103 / \mu \mathrm{l}$ and white blood cell count of $6.9 \times 10^{3} / \mu \mathrm{l}$. Serum electrolytes were as follows: $\mathrm{Na} 136 \mathrm{mmol} / \mathrm{l}, \mathrm{K} 3.6 \mathrm{mmol} / \mathrm{l}, \mathrm{Cl} 105 \mathrm{mmol} / \mathrm{l}, \mathrm{HCO}_{3} 23 \mathrm{mmol} / \mathrm{l}$, BUN $10 \mathrm{mg} / \mathrm{dl}$ and creatinine $1.3 \mathrm{mg} / \mathrm{dl}$. She was admitted to the hospital mainly for symptom control and further evaluation. She was started on supportive therapy with intravenous hydration and anti-nausea medications. She had a right upper quadrant ultrasound that showed some stones within the gallbladder, but no findings suggestive of acute cholecystitis. A HIDA scan was also done and came back negative. After a few days, her symptoms worsened. Gastroenterology was consulted and she had an EGD that showed mild esophagitis for which she was placed on a proton pump inhibitor. Serial daily labs including complete blood count and basic metabolic profile did not reveal any abnormalities.

While in the hospital, she was noticed to have a positive Babinski's test on daily physical examination, which was a new finding that had been absent on presentation. At this point, she gave a remote history of blackout spells. Following this, she had a head CT that turned up negative. An EEG was also obtained which showed normal awake and sleep patterns. She had an MRI without contrast showing moderate diffuse atrophy, most particularly in the 
occipital area (she denied any prior head trauma or problems at birth) and very few scattered white matter hyperintensities (she has a history of tobacco abuse). She went on to have a brain MRI with and without contrast with results showing small foci of linear abnormal T2 signal with questionable associated vague enhancement at the posterior aspect of the brainstem, in the region that anatomically corresponds to the area postrema (fig. 1, fig. 2, fig. 3). This finding was suspicious for a variant presentation of NMO with intractable nausea/vomiting. Following this finding, she was started on $1 \mathrm{~g}$ of IV Solu-Medrol daily. The day after her first dose of Solu-Medrol, she was symptom-free and asked for a diet, which she tolerated well. Blood work was sent out for NMO autoantibodies. Results were not back prior to discharge. Neurology recommended a lumbar puncture to evaluate for MS. However, the patient started feeling better on Solu-Medrol and deferred the procedure, saying she would consider it if her symptoms recurred. After 5 days on IV Solu-Medrol and still symptom-free, she was transitioned to oral steroids and discharged with a taper. She was asked to follow up with the Neurology Clinic and her primary care doctor. After discharge, her NMO autoantibodies came back positive. She also had a low vitamin $B_{12}$ level of $227 \mathrm{pg} / \mathrm{ml}$. Other lab work done included TSH, RPR, heavy metals, UDS and serum ACE, which all came back negative or within normal range. At the clinic, she was started on rituximab and has remained symptom-free till the writing of this article.

\section{Discussion}

Intractable nausea and vomiting is a commonly encountered problem in any general medicine or gastroenterology service. Several causes from infection to chronic medical conditions, such as diabetic gastroparesis and gastroparesis due to multiple causes, can be listed. NMO, also known as Devic's disease, is a rare autoimmune disorder in which a patient's immune system affects the optic nerves and spinal cord, leading to loss of vision and spinal cord dysfunction [1-3]. Spinal cord dysfunction is mainly manifested as weakness, paralysis, numbness and possibly bowel and bladder incontinence. Due to these symptoms, NMO can often be confused with MS. As rare a disease as NMO is, it is even rarer for intractable nausea and vomiting to be the only initial presenting symptoms, and this is sparsely mentioned in reviewed literature [4]. NMO is caused by the development of autoantibodies (NMO-IgG) against the protein aquaporin 4 found in the cell membranes of the processes of astrocytes that surround and protect the blood brain barrier. Like in MS, demyelination of the optic nerve and spinal cord is also known to occur in NMO, but the exact mechanism is still to be described. However, astrocyte destruction is thought to be more severe than demyelination and as such probably plays a bigger role in the pathogenesis of the disease [5].

Wingerchuk et al. [6] from the Mayo Clinic proposed revised criteria for diagnosing NMO. They considered the presence of optic neuritis and myelitis as absolute criteria. They proposed that at least two out of three supporting criteria in addition to the above-listed absolute criteria are needed to make a diagnosis of NMO. The three supporting criteria are: (1) A contiguous spinal cord lesion on MRI extending over three or more segments. (2) Initial brain MRI not meeting the usual diagnostic criteria for MS. (3) Seropositivity for NMO-IgG.

Lennon et al. [7] conducted a case-control study on the sensitivity and specificity of NMO-IgG in the diagnosis of the disease and concluded that sensitivity and specificity were $73 \%$ (95\% CI 60-86) and 91\% (95\% CI 79-100) for NMO. NMO-IgG was detected in half of patients with high-risk syndromes. Of 14 seropositive cases identified incidentally, 12 had NMO or a high-risk syndrome for the disease. Different variants of the disease with unique 
Enweluzo et al.: Neuromyelitis Optica: An Often Forgotten Cause of Intractable Nausea and Vomiting

presenting features have been described. In a case series, Apiwattanakul et al. [8] reported on 12 aquaporin 4 antibody-positive patients $(12 \%$ of seropositive Mayo Clinic patients identified since 2005) whose initial presenting symptom of NMO was intractable vomiting. The initial evaluation in 75\% was gastroenterological. Vomiting lasted a median of 4 weeks (range 2 days to 80 weeks). Optic neuritis or transverse myelitis developed after vomiting onset in 11 patients. At last evaluation (median 48 months after vomiting onset), 7 patients fulfilled the diagnostic criteria for NMO. From their study they suggested that the aquaporin 4-rich area postrema might be a first point of attack in NMO [8, 9]. The disease has recently been associated with several comorbid conditions including collagen vascular diseases, autoantibody syndromes, infections with varicella zoster virus, Epstein-Barr virus and HIV, and exposure to clioquinol and anti-tuberculosis drugs [10]. A high level of suspicion on the part of the clinician is necessary for early diagnosis, especially in cases where the only initial presenting symptoms are nausea and vomiting. It is also pertinent to note that NMO-IgGnegative disease has been described as well, making diagnosis in these circumstances quite challenging [11].

In terms of treatment, the goal is to control symptoms in acute attacks and to maintain a 'safe' level of immunosuppression on a chronic state. Presently, there is no cure for the disease. Intravenous glucocorticoid (typically $1 \mathrm{~g}$ of IV Solu-Medrol daily over 5 days) is the recommended treatment during acute attacks. Azathioprine, mycophenolate mofetil or rituximab is used to achieve immunosuppression on a chronic state, thereby preventing relapse. Patients will typically require this for at least 5 years (especially if they are NMO-IgGseropositive) even if they have had just one attack $[12,13]$. It is our hope that our experience and this article highlight a less often considered cause of intractable nausea and vomiting. If this had been considered earlier, this patient could have achieved a quicker turnaround, with improved health outcomes and cost.

\section{Disclosure Statement}

The authors declare no conflict of interest. There was no grant support.

\section{References}

1 Wingerchuk DM, Lennon VA, Lucchinetti CF, et al: The spectrum of neuromyelitis optica. Lancet Neurol 2007;6:805-815.

2 Wingerchuk DM, Hogancamp WF, O’Brien PC, Weinshenker BG: The clinical course of neuromyelitis optica (Devic's syndrome). Neurology 1999;53:1107-1114.

3 Mandler RN, Davis LE, Jeffery DR, Kornfeld M: Devic's neuromyelitis optica: a clinicopathological study of 8 patients. Ann Neurol 1993;34:162-168.

4 Popescu BF, Lennon VA, Parisi JE, et al: Neuromyelitis optica unique area postrema lesions: nausea, vomiting, and pathogenic implications. Neurology 2011;76:1229-1237.

5 Takano R, Misu T, Takahashi T, et al: Astrocytic damage is far more severe than demyelination in NMO: a clinical CSF biomarker study. Neurology 2010;75:208-216.

-6 Wingerchuk DM, Lennon VA, Pittock SJ, et al: Revised diagnostic criteria for neuromyelitis optica. Neurology 2006;66:1485-1489.

7 Lennon VA, Wingerchuk DM, Kryzer TJ, et al: A serum autoantibody marker of neuromyelitis optica: distinction from multiple sclerosis. Lancet 2004;364:2106-2112.

8 Apiwattanakul M, Popescu BF, Matiello M, et al: Intractable vomiting as the initial presentation of neuromyelitis optica. Ann Neurol 2010;68:757-761.

-9 Jarius S, Franciotta D, Bergamaschi R, et al: NMO-IgG in the diagnosis of neuromyelitis optica. Neurology 2007;68:1076-1077.

$>10$ Cree BA, Goodin DS, Hauser SL: Neuromyelitis optica. Semin Neurol 2002;22:105-122. 


\section{Case Reports in
Gastroenterology}

\begin{tabular}{l|l}
\hline Case Rep Gastroenterol 2013;7:281-286 \\
\hline DOI: $10.1159 / 000354145$ & $\begin{array}{l}\text { @ } 2013 \text { S. Karger AG, Basel } \\
\text { www.karger.com/crg }\end{array}$ \\
\hline
\end{tabular}

Enweluzo et al.: Neuromyelitis Optica: An Often Forgotten Cause of Intractable Nausea and Vomiting

11 Marignier R, Bernard-Valnet R, Giraudon P, Collongues N, Papeix C, Zéphir H, Cavillon G, Rogemond V, Casey R, Frangoulis B, De Sèze J, Vukusic S, Honnorat J, Confavreux C; for the NOMADMUS Study Group: Aquaporin-4 antibody-negative neuromyelitis optica: distinct assay sensitivity-dependent entity. Neurology 2013;80:2194-2200.

12 Wingerchuk DM, Weinshenker BG: Neuromyelitis optica. Curr Treat Options Neurol 2008;10:55-66.

13 Carroll WM, Fujihara K: Neuromyelitis optica. Curr Treat Options Neurol 2010;12:244-255.

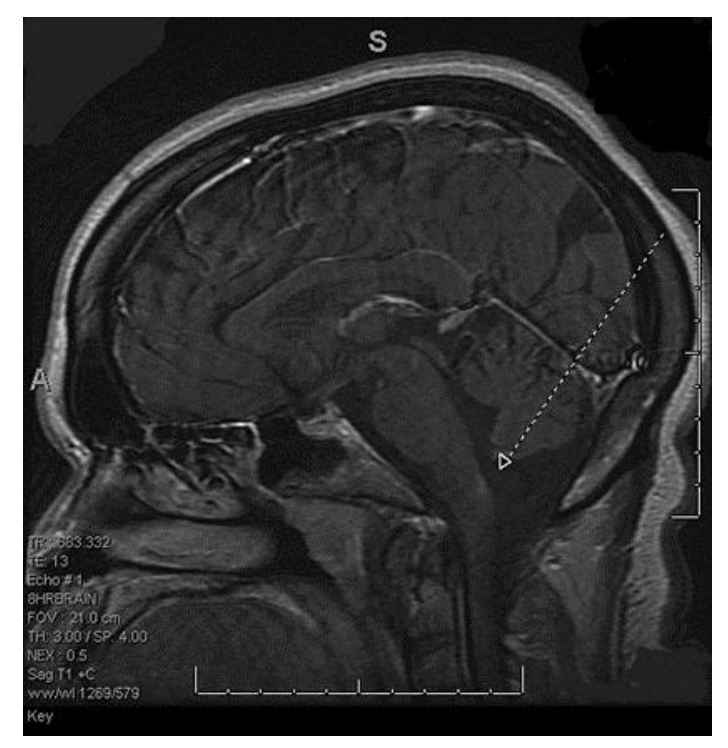

Fig. 1. Brain MRI with and without contrast. The arrow indicates the abnormal, tiny foci of T2 signal abnormality at the posterior aspect of the brainstem along the foramen of Magendie, corresponding to the anatomic region of the area postrema.

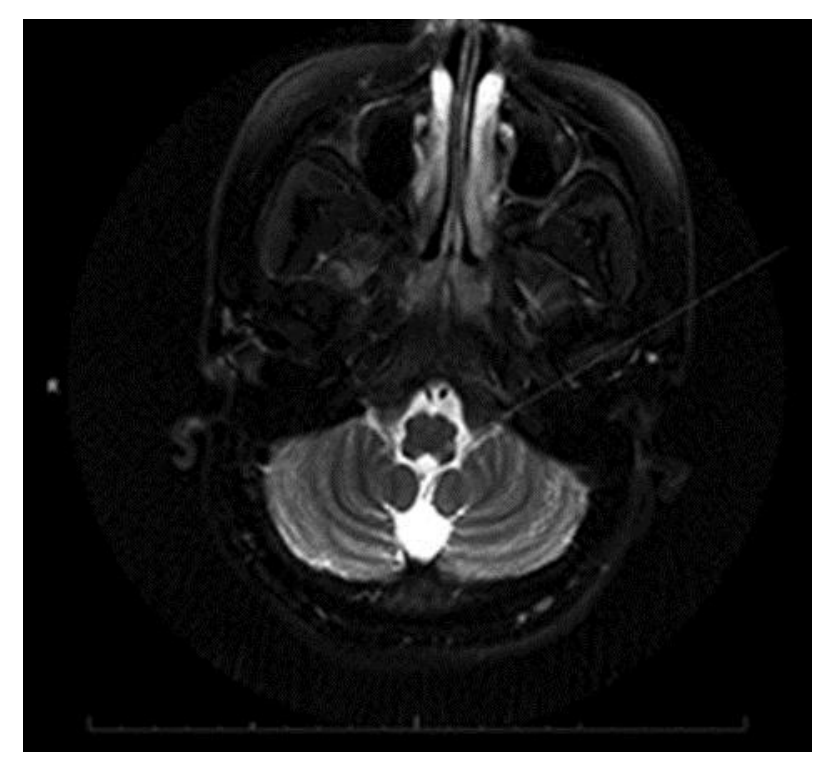

Fig. 2. Brain MRI with and without contrast. The arrow indicates an area of vague enhancement on the surface of the brainstem associated with the left-sided T2 signal abnormality. 


\begin{tabular}{|c|c|c|}
\hline \multirow{2}{*}{$\begin{array}{l}\text { Case Reports in } \\
\text { Gastroenterology }\end{array}$} & \multicolumn{2}{|c|}{ Case Rep Gastroenterol 2013;7:281-286 } \\
\hline & DOI: $10.1159 / 000354145$ & $\begin{array}{l}\text { (c) } 2013 \text { S. Karger AG, Basel } \\
\text { www.karger.com/crg }\end{array}$ \\
\hline
\end{tabular}

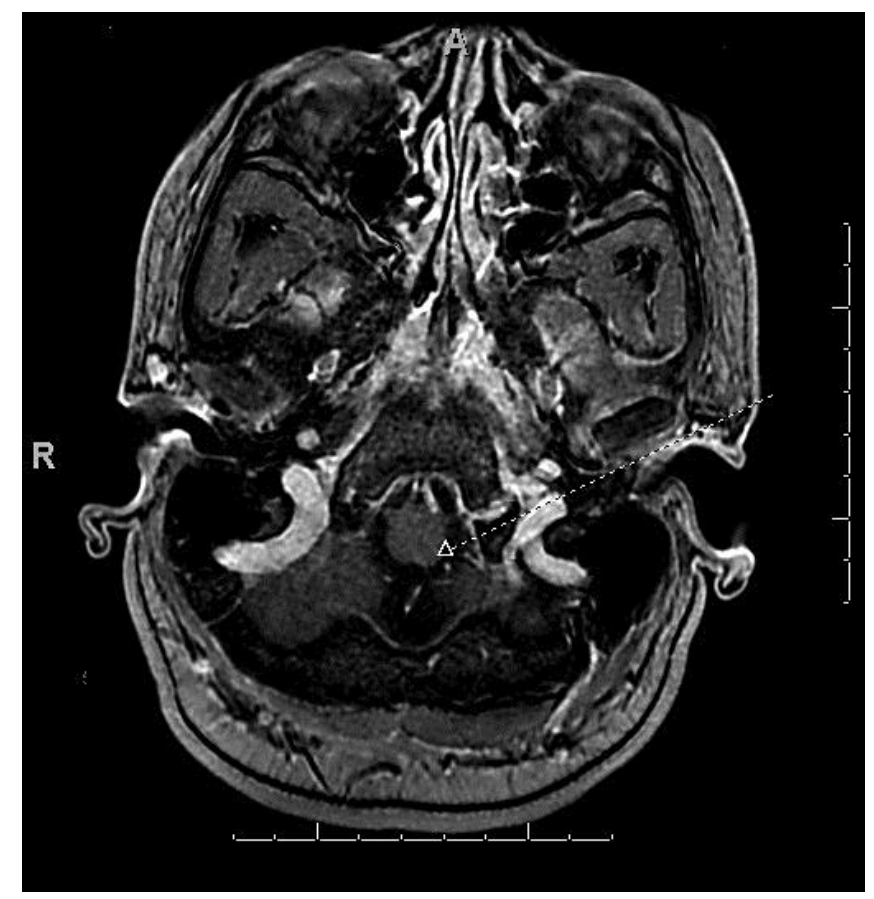

Fig. 3. Brain MRI with and without contrast, sagittal view. The arrow indicates T1 post gadolinium sequences also demonstrating questionable vague enhancement in the same area, extending in a linear fashion towards the central canal. 